\title{
New Route for Novel Polycarboxylic Starch Hybrid
}

\author{
Ali Hebeish ${ }^{1}$, Abdul Rhman Mousa ${ }^{2}$, Mohamed A. Ramadan ${ }^{1}$, Amany Saleh $^{1}$ \\ ${ }^{1}$ National Research Centre, Textile Research Division, Cairo, Egypt; ${ }^{2}$ Chemistry Department, Faculty of Science, Ain Shams Univer- \\ sity, Cairo, Egypt. \\ Email: amaramadan1@hotmail.com
}

Received September $22^{\text {nd }}, 2013$; revised October $23^{\text {rd }}, 2013$; accepted November $4^{\text {th }}, 2013$

Copyright (C) 2013 Ali Hebeish et al. This is an open access article distributed under the Creative Commons Attribution License, which permits unrestricted use, distribution, and reproduction in any medium, provided the original work is properly cited.

\begin{abstract}
Starch was polymerized with methacrylic acid (MAA) to different magnitudes of poly (MAA) using potassium persulphate/sodium thiosulphate redox initiation system. The polymerization products are referred to as "composite". The latter consists of poly (MAA)-starch graft copolymer, poly (MAA) in the form of homopolymer, oxidized starch brought about under the influence of the initiator and intact starch. At this end, the composite, the copolymer, and the untreated (native) starch were subjected to carboxymethylation under different conditions and the rheological properties of these starch — based on products before and after carboxymethylation examined. Results obtained disclosed that the susceptibility of these products toward carboxymethylation follows the order: native starch $>$ Copolymer $>$ composite. Meanwhile, these products exhibit non-Newtonian thixotropic behavior before carboxymethylation; and their rheology signifies the order: Composite $>$ copolymer $>$ native starch whereas after carboxymethylation these products are characterized by non-Newtonian Pseudoplastic behavior. For a given rate of shear, the apparent viscosity follows the order: native starch $>$ composite $>$ copolymer $>$ carboxymethyl composite $>$ carboxymethyl starch $>$ carboxymethyl copolymer, in contrast with pseudoplasticity which reveals an opposite order. It was also shown that the apparent viscosity increases by increasing poly (MAA) in the copolymer and composite and that redrying of the copolymer and the composite after normal precipitation and drying causes a considerable enhancement in the apparent viscosity of these products.
\end{abstract}

Keywords: Starch; Copolymer Material; Carboxymethylation; Methacrylic Acid; Composite Material

\section{Introduction}

Starch is widely used in different industries [1]. Textile industry, for example, uses large quantities of starch in warp yarn sizing [2], printing and finishing [3]. In common practice, however, modified starches are usually employed since the properties of native starch cannot cope with those required for such purposes as well as for other particular end-use [4,5].

Starch undergoes chemical modification when it is subjected to oxidation [6], hydrolysis, esterification [7], etherification), grafting [8], and cross-linking [9]. Combined hydrolysis (or oxidation) and grafting [6] are also used to effect starch modification.

The reaction involved in the chemical modification of starch causes significant changes in its physical as well as in its chemical structure. As a result, the solubility, viscosity performance, film-forming properties, resistance to ageing, etc. can be adjusted as per the end use required. Indeed, newly synthesized polymeric materials based on starch present a very fascinating field of research with unlimited future possibilities for promotion of starch utilization. Furthermore, starch is one of the most effective bioresource for technologies such as nanotechnology [7].

With the above in mind, current work presents an innovative route for synthesis of novel starch hybrid, namely, polycarboxylic starches. The innovation is based on carboxymethylation of poly (MAA)-starch graft copolymer as well as poly (MAA)-Starch composite vis-avis native starch. These starch hybrids are monitored for carboxyl content and rheological properties.

\section{Experimental}

\subsection{Materials}

Maize starch was supplied by the Egyptian Starch and Glucose manufacturing Company, Cairo, Egypt. Methacrylic acid (MAA), sodium hydroxide, monochloroacetic 
acid, potassium persulphate, sodium thiosulphate, hydrochloric acid, sodium carbonate, ethanol, and acetone were of laboratory grade chemicals.

\subsection{Grafting Method}

Unless otherwise indicated, the grafted starch was prepared by mixing $10 \mathrm{~g}$ starch with $100 \mathrm{ml}$ water in a flask. The latter was placed in a thermostatic water bath adjusted at $65^{\circ} \mathrm{C}$, and the starch/water mixture therein was subjected to continuous mechanical stirring $(200 \mathrm{rpm})$ to get homogenized slurry. MAA monomer $\{75 \%$ based on weight of starch, (ows) $\}$ was then added to the homogenized slurry while stirring. After that, the components of redox initiator system were added simultaneously. This system consisted of a sodium thiosulphate at concentration of $1.1 \mathrm{mmol} / 1$ and potassium persulphate $3.3 \mathrm{mmol} / 1$. Polymerization system was allowed to proceed for 60 minutes at $65^{\circ} \mathrm{C}$ with continuous stirring. The material to liquor ratio was 1:10. After 60 minutes-reaction, polymerization was ceased by adding $10 \mathrm{ml}$ of $0.1 \%$ hydroquinone solution. At this end, the polymerization products in the flask were neutralized using $1 \%$ sodium carbonate solution then poured over ethanol, where a precipitate was formed. The so obtained precipitate is referred to as "composite". The latter consists of Poly (MAA)-starch graft copolymer, poly (MAA) (homopolymer), oxidized starch, and unreacted starch. The composite was soxhlet extracted using methanol to remove the homopolymer. The residual precipitate represents the poly (MAA)-starch graft copolymer.

\subsection{Carboxymethylation Method}

Unless otherwise stated carboxy-methylation of starch, Poly (MAA)-starch composite and Poly (MAA)-starch graft copolymer was carried out as follow: sodium hydroxide solution ( $20 \%$ ows), was added gradually to 100 $\mathrm{g}$ starch in a flask with continuous mechanical stirring (200 rpm). This was followed by addition of monochloroacetic acid solution (95\% ows) after being neutralized with sodium carbonate while stirring. Stirring was continued till the flask contents were completely homogenized. The flask was then transferred to a thermostatic water bath and reaction was allowed to proceed under continuous mechanical stirring at $70^{\circ} \mathrm{C}$ for 120 minutes. At this end, the reaction product was precipitated and washed several times in ethanol then dried at $50^{\circ} \mathrm{C}$ in an oven [10].

\subsection{Cooking Process}

An aqueous dispersion of starch or the modified starches under investigation was prepared at a concentration of $10 \%$ solid content. The dispersion was then homogenized before heating by use of a mechanical stirrer $(250 \mathrm{rpm})$ for 10 minutes. Cooking was effected by heating the sample under continuous stirring in a thermostatic water bath where the temperature was raised from $25^{\circ} \mathrm{C}$ to $95^{\circ} \mathrm{C}$ in a rate of $2.5^{\circ} \mathrm{C}$ per minute then kept constant at $95^{\circ} \mathrm{C}$ for 30 minutes cooking to bring about a paste. Temperature of this paste was lowered to $25^{\circ} \mathrm{C}$; meanwhile stirring was reduced to the minimum degree within $15 \mathrm{~min}-$ utes.

\subsection{Analysis}

The carboxyl content of starch and the modified starches viz. the copolymer and the composite before and after etherification via carboxymethylation was determined according to a reported method [11], which is based on acid-base titration.

The rheological properties were measured using Roto-Visco RV 20 under the following experimental conditions. Rate of shear was between $129-1290 \mathrm{~S}^{-1}$ and temperature $80^{\circ} \mathrm{C}$. The apparent viscosity was calculated using the following formula

$$
\eta: \mathrm{St} / \mathrm{D}
$$

where:

$\eta$ : apparent viscosity (mPa.S), D: rate of shear $\left(\mathrm{S}^{-1}\right), \mathrm{St}$ : shear stress $(\mathrm{mPa})$.

\section{Results and Discussion}

\subsection{Tentative Mechanisms}

Etherification of starch via reaction with monochloroacetic acid in presence of sodium hydroxide has been extensively studied [7]. The essential product of this reaction is the well-known carboxymethyl starch, CMS, which is commercially available in different types. Reaction involved in carboxymrthylation of starch was reported. Polymerization of starch with acrylic monomers has also been a subject of many investigations [12]. The polymerization process comprises a system consisting of starch, MAA monomer, $\mathrm{K}_{2} \mathrm{~S}_{2} \mathrm{O}_{8} / \mathrm{Na}_{2} \mathrm{~S}_{2} \mathrm{O}_{3}$ redox initiator and water. The system is very complex since it entails several reactions which may be outlined as follows: a) The redox initiator decomposes to yield primary free radial species, namely, sulphate ion radical hydroxyl radicals, and, thiosulphate ion free radicals. b) These free radicals attack the starch hydroxyl where a hydrogen atom is abstracted thereby producing starch macroradical capable of initiating grafting of MAA. c) The primary free radicals can add to double bond of MAA and in so doing, the monomer molecule is converted to an excited state which can initiate the growth of a polymer via subsequent addition of monomer molecule. d) The primary free radicals attack the starch to give starch macroradicals which add oxygen and lend itself to an oxidative degradation process. 
Obviously, then, the essential products of polymerization of MAA with starch are: poly (MAA)-starch graft copolymer formed according to d). In addition to these products intact starch is expected to be among the ultimate end products of the polymerization process. Thus when polymerization products are considered we are indeed dealing with a composite consisting of all these products taken together. The word starch hybrids is used in this work to refer to the composite and/or the copolymer after being subjected to carboxymethylation.

Needless to say those, the carboxy-methylation of starch as well as its polymerization with acrylic acid and other vinyl monomers have gained much attention. On the contrary, no work so far has been published on the behavior of starch graft copolymer or starch composite towards carboxymethylation under different conditions. The present work is undertaken as an endeavor to fulfill this gap. Products of polymerization of starch with MAA before and after carboxy-methylation were analyzed for carboxyl content and rheological products and the results obtained are presented and discussed as given under.

\subsection{Carboxyl Content}

\subsubsection{Dependence of the Carboxyl Groups of Starch Due to Carboxymethylation on the Magnitude of Poly (MAA) Content}

Table 1 shows the dependence of carboxymethylation on the MAA concentration used in synthesis of the copolymer of starch and starch composite. The monomer concentration is taken as a measure for the magnitude of poly (MAA) content in both copolymer and composite. This magnitude as well as the extent of carboxymethylation is expressed as m.eq. $\mathrm{COOH} / 100 \mathrm{~g}$ starch.

It is seen (Table 1) that using MAA concentration of $50 \%, 75 \%$, and $100 \%$, ows, brings about composite having 140,172 , and 190 meq.COOH/100g starch. This is rather expected since the poly (MAA) in the composite is directly related to the monomer concentration within this range (50\% - 100\% ows). Similar observation is encoun-

Table 1. Effect of MAA concentration on the carboxyl content of native starch, composite, and graft copolymer before and after carboxymethylation.

\begin{tabular}{ccccccc}
\hline \multirow{2}{*}{$\begin{array}{c}\text { MAA }] \\
(\%)\end{array}$} & \multicolumn{3}{c}{ Carboxyl content (m.eq COOH/100g sample) } \\
\cline { 2 - 7 } & \multicolumn{3}{c}{ Composite } & \multicolumn{4}{c}{ Graft copolymer } \\
\hline 0 & 0.16 & 95.4 & 95 & 0.16 & 95.4 & 95 \\
50 & 140 & 166 & 36 & 133 & 190 & 57 \\
75 & 172 & 192 & 20 & 160 & 206 & 46 \\
100 & 190 & 201 & 11 & 179 & 210 & 31 \\
\hline
\end{tabular}

bc: before carboxymethylation; ac: after carboxymethylation; c: the increment in carboxyl content due to carboxymethylation. tered with the copolymer but with lower carboxyl contents as a result of homopoly (MAA) removal from the composite. Subjecting the composite and copolymer to carboxymethylation causes an enhancement in their carboxyl contents. However, it is certain a) that the carboxyl content due to carboxymethylation is much higher with the copolymer than the composite, b) that the higher the graft yield of the copolymer or the composite the lower the carboxyl content due to carboxymethylation and c) that the carboxyl content of starch due to carboxymethylation is significantly higher than the corresponding values of the copolymer and the composite. These findings lead to three main conclusions. First the composite is less susceptible to carboxymethylation than the copolymer by virtue of the presence of homopoly (MAA) which is inert to carboxymethylation. Second the magnitude of poly (MAA) in the form of graft or homopolymer adversely affect the carboxymethylation reaction by blocking some of starch hydroxyls and/or lowering the accessibility of starch through the ultimate association and physical entanglement of the poly (MAA) with the starch molecules. The third conclusion refers to the greater amenability of native starch to carboxymethylation as compared with the copolymer and the composite; a point which indeed is in full conformation with the first and second conclusions.

\subsubsection{Concentration of Sodium Hydroxide}

Figures 1-4 show different factors affecting the extent of carboxymethylation, expressed as carboxyl contents. One of these factors the concentration of sodium hydroxide. For this reason the carboxymethylation of the poly (MAA)starch graft copolymer having 160 meq.COOH/100g sample was carried out using sodium hydroxide concentration within a range of $0 \%-40 \%$ ows. The results obtained are shown in Figure 1.

Results of Figure 1 signify that carboxyl content of the copolymer due to carboxymethylation increases significantly by increasing the concentration of sodium hydroxide up to $20 \%$ ows. Above $20 \%$ the carboxyl content decreases sharply. That is, $20 \%$ sodium hydroxide concentration constitutes the optimum alkaline catalyst concentration for carboxymethylation since below or above this particular concentration lower extent of etherification is observed.

It seems likely that at $20 \%$ sodium hydroxide concentration, swelling of the copolymer with subsequent ease of diffusion of monochloroacetic acid are in full swing thereby enhancing the extent of carboxymethylation. Higher sodium hydroxide concentrations seems to function more in favour of gluconate formation and other side reactions which occur at the expense of carboxymethylation. Also likely to occur are de-etherification and degrafting, i.e., splitting off of the carboxymethyl group 


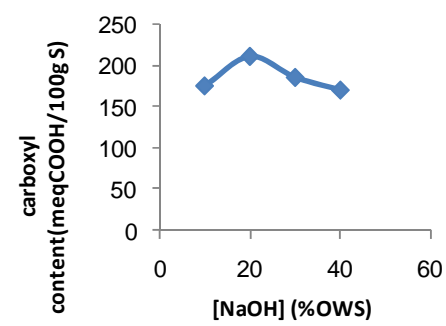

Figure 1. Effect of sodium hydroxide concentration on the extent of carboxymethylation.

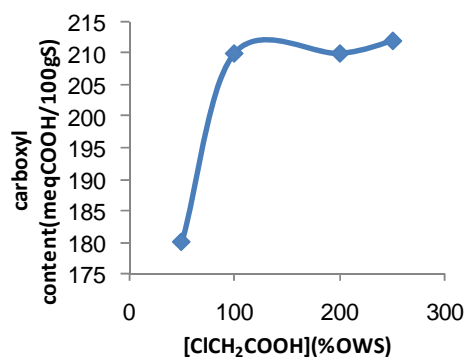

Figure 2. Effect of monochloroacetic acid concentration on the extent of carboxymethylation.

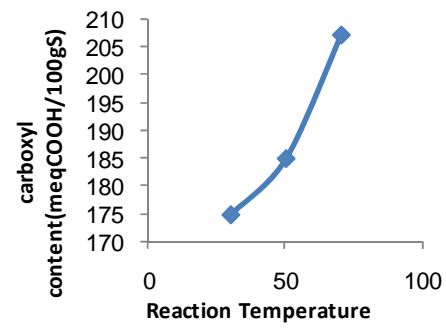

Figure 3. Effect of reaction temperature on the extent of carboxymethylation.

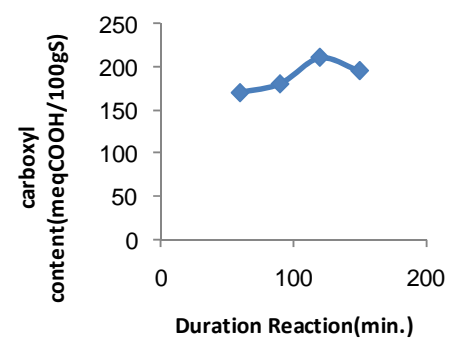

Figure 4. Effect of duration of carboxymethylation on the extent of carboxymethylation.

and the graft under the influence of sodium hydroxide concentration higher than $20 \%$, ows.

\subsubsection{Concentration of Monochloro-Acetic Acid}

Another factor which governs the extent of carboxymethylation is monochloroacetic acid concentration. In accordance with previous reports dealing with starch [11], the extent of carboxymethylation of poly (MAA)-starch graft copolymer increases by increasing monochloroacetic acid concentration up to $95 \%$ ows, above which there is only a marginal increase This is clearly shown in Figure 2.

The significant enhancement in carboxymethylation by increasing monochloroacetic acid up to $95 \%$ ows, could be associated with greater availability of chloroacetic acid molecules in the vicinity of starch. It is understandable that the hydroxyls of starch are immobile and their reaction with monochloroacetic acid $\left(\mathrm{ClCH}_{2} \mathrm{COOH}\right)$ and sodium hydroxide molecules would essentially depend upon availability of $\mathrm{ClCH}_{2} \mathrm{COOH}$ and $\mathrm{NaOH}$ molecules in the proximity of the hydroxyl groups of starch molecules. On the other hand, the marginal increment of carboxymethylation could be interpreted in terms of reduction of the amount of hydroxyl group available on the starch molecules.

It seems that there is a certain amount of accessible hydroxyl group in the molecular structure of starch. Once these groups are blocked via graft polymerization and carboxymethylation, and/or accessible domains are removed under induced solubility, further reaction becomes difficult under the applied conditions. That is besides blocking starch hydroxyls during the carboxymethylation reaction, starch undergoes some changes which diminishes the susceptibility of starchtowards further etherification.

\subsubsection{Temperature of Carboxymethylation}

Figure 3 shows the effect of temperature on carboxymethylation of poly (MAA)-starch graft copolymer. As is evident the extent of carboxymethylation, expressed as carboxyl content, increases by raising the temperature within the range $30^{\circ} \mathrm{C}-70^{\circ} \mathrm{C}$. This could be associated with the favourable effect of temperature on a) swelling of the copolymer, b) diffusion of etherifying agents in the interior of the copolymer, c) formation of sodium starchate (St-O-Na), d) neutralization of monochloroacetic to from $\mathrm{ClCH}_{2} \mathrm{COONa}$ which is more reactive than the acid form, $\mathrm{ClCH}_{2} \mathrm{COOH}$, and e) temperature which provides an additional energy source for faster mobility and collision of reactants and, therefore, greater carboxymethylation.

\subsubsection{Duration of Carboxymethylation}

Figure 4 shows the carboxyl content (expressed as meq $\mathrm{COOH} / 100 \mathrm{~g}$ sample) of the copolymer versus the time of carboxymethylation. It is evident that prolonging the duration of carboxymethylation up to 120 minutes enhanced significantly the extent of carboxymethylation then decreases thereafter. This state affairs calls for the favourable effect of time as a very important factor which allows better contact between reactants for reaction to occur. Meanwhile it reflects the opposite effect of time on carboxymethylation to undergo de-etherification and degrafting as well as depletion in etherifying agents 
concentration through side reactions.

\subsection{Optimum Conditions}

Based on the results of Figures 1-4 discussed above, it may be concluded that the most appropriate conditions for carboxymethylation of poly (MAA)-starch graft copolymer are as follows: sodium hydroxide, $20 \%$ ows; monochloroacetic acid, 95\% ows; reaction time, 120 minutes and; reaction temperature, $70^{\circ} \mathrm{C}$.

\subsection{Rheological Properties}

\subsubsection{Shear Stress versus Rate of Shear}

To start with, starch and all other starch products derived thereof were cooked under conditions described in the experimental section.

The correlation between shear stress (St) and rate of shear (D) defining the flow curve of flow behavior of a liquid is graphically displayed in diagram of $(\mathrm{St})$ on the ordinate and D on the abscissa. This diagram is called flow curve. Figures 5-9 show the flow curve diagrams (saved as Excel figures), which are produced directly from HAAKE ROTO Visco RV 20 viscometer equipment at $80^{\circ} \mathrm{C}$ for native maize starch, poly (MAA)starch graft copolymer, starch composite and their carboxymethylated products when MAA was used at concentrations of $50 \%, 75 \%$ and $100 \%$ ows for the preparation of the copolymer and the composite.

The flow curve diagrams Figures 5-9 signify that the shear stress increases as the rate of shear increases from zero to $1290 \mathrm{~s}^{-1}$. Opposite situation is encountered by decreasing the rate of shear from the maximum $1290 \mathrm{~s}^{-1}$ to zero. This indicates that the starch and the products derived thereof are characterized by non-Newtonain behavior. However, a close examination of the up and down flow curves would reveal that these curves are not coincident in the case of native starch, the copolymer and the composite, indicating that these starch products exhibit thixotropic behavior. One the other hand, the carboxymethylated products derived from native starch, the

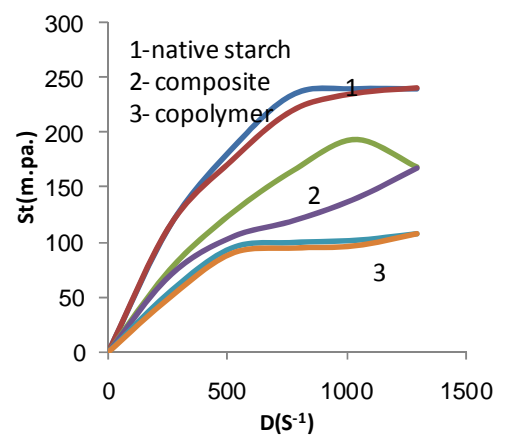

Figure 5. Shear stress (St) versus rate of shear (D) for native starch, composite and copolymer at $50 \%$ MAA concentration before carboxymethylation.

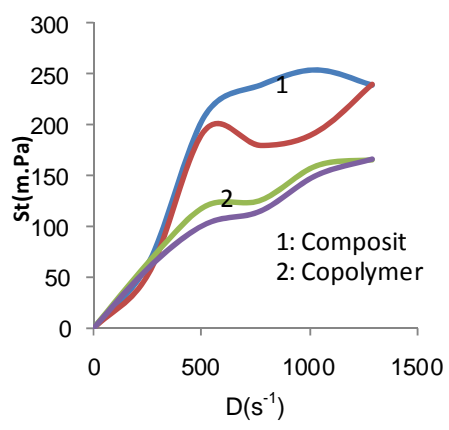

Figure 6. Shear stress versus rate of shear for composite and copolymer at $\mathbf{7 5 \%}$ MAA concentration before carboxymethylation.

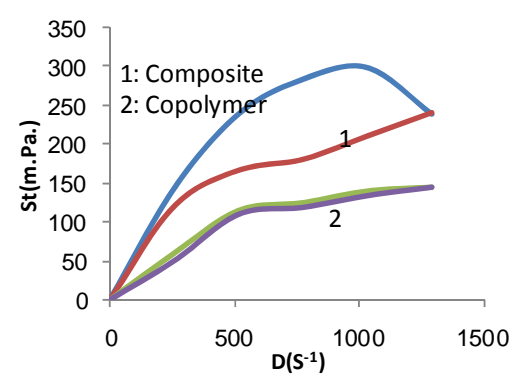

Figure 7. Shear stress versus rate of shear for composite and copolymer at $100 \%$ MAA concentration before carboxymethylation.

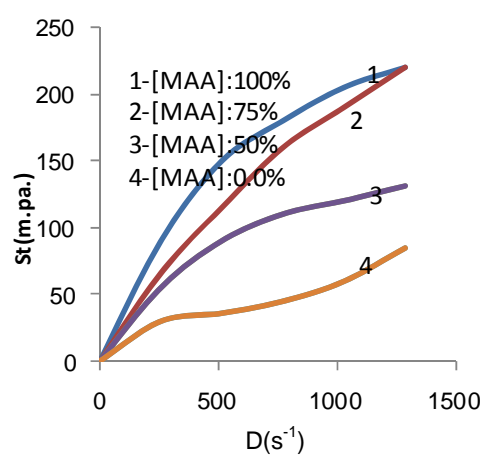

Figure 8. Rheogram of the composite prepared using different MAA concentrations and native starch after being carboxymethylated.

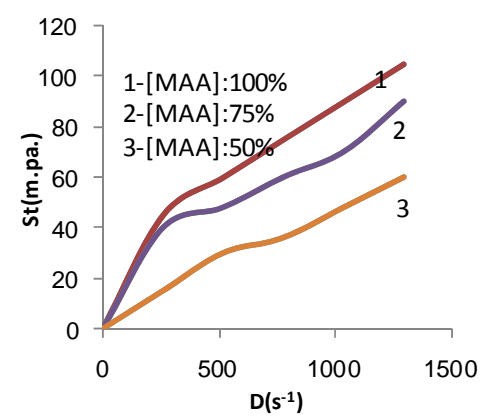

Figure 9. Rheogram of the graft copolymer prepared using different MAA concentrations after being carboxymethylated. 
copolymer and the composite are characterized by pseudoplastic behavior because the up and the down flow curves are coincident. This implies that introduction of caboxymethyl group in the molecular structure of the products under investigation induces the ability of the macromolecules of these products to rebuild immediately after the applied force is removed.

It is further noted that the rheogram of native starch is the farest one from the axis of the rate of shear, indicating the highest apparent viscosity while that of the carboxymethyl copolymer i.e. carboxymethyl poly (MAA)starch graft copolymers is the nearest indicating the lowest apparent viscosity.

\subsubsection{Apparent Viscosity}

The apparent viscosities of the cooked solutions of native starch as well as those of poly (MAA)-starch graft copolymers, poly (MAA)-starch composites, carboxymethyl poly (MAA)-starch graft copolymers and carboxymethyl composites were measured at different rate of shear. The rate of shear ranges from 129 to $1290 \mathrm{~s} \mathrm{~s}^{-1}$. The measuring temperature was $80^{\circ} \mathrm{C}$ and the concentration of starch products was $10 \%$.

Figure 10 shows the flow profile curves of the native starch, the copolymer and the composite before and after carboxymethylation. MAA at concentration of $50 \%$ ows, was used in the preparation of the copolymer and the composite. It is clear that the apparent viscosity decreases by increasing the rate of shear regardless of the nature of the starch products used. However, nature of starch determines the apparent viscosity. For a given rate of shear up to $1000 \mathrm{~s}^{-1}$ the apparent viscosity follows the order: native starch $>$ composite $>$ copolymer $>$ caboxymethyl composite $>$ carboxymethyl starch $>$ carboxymethyl copolymer. This is also valid at rates of shear higher than $1000 \mathrm{~s}^{-1}$ except that the apparent viscosity of the composite becomes equal to the apparent viscosity of carboxymethyl starch. It follows from this that the native starch undergoes oxidative degradation

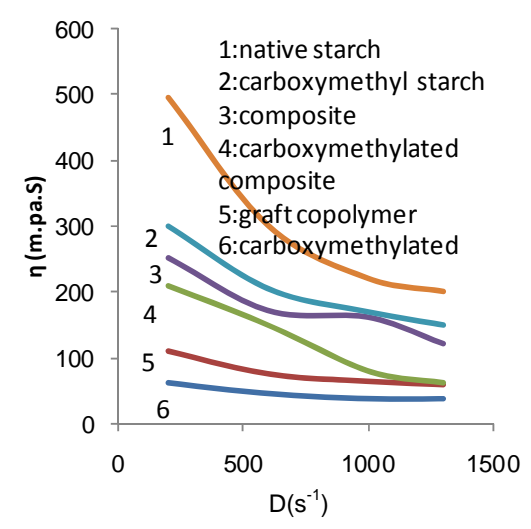

Figure 10. Effect of rate of shear on apparent viscosity when $50 \%$ MAA was used in the polymerization reaction. during the polymerization process under the influence of the initiator. This fall in molecular size of starch in combination with the increased solubility by the presence of poly (MAA) would account for the lower apparent viscosity of the composite and the graft copolymer when compared with native starch. Carboxymethylation causes further reduction in the molecular sizes of starch composite and starch copolymer by oxidative degradation occurring during the substitution process. Introduction of solubilizing group such as carboxymethyl groups will enhance the solubility. Hence the solubility and the low molecular mass of the carboxymethyl starch products are responsible for the decrease in apparent viscosity. It is known that the viscosity decreases when the solubility increases.

Figures 11 and 12 show the apparent viscosity as a function of the rate of shear for the six starch substrates under investigation when the polymerization was conducted using MAA at $75 \%$ and $100 \%$ ows. Here too, the apparent viscosity decreases as the rate of shear increases irrespective of the starch substrate used. Nevertheless the flow profile curve of the carboxymethyl graft copolymer is very close to that of the carboxymethyl starch (Figure 11). Similarly the flow profile curves of native starch, composite, carboxymethyl composite become closer (Figure 12). The flow profile curves, namely, native starch, composite, carboxymethyl composite and the graft copolymer have become also closer as compared when $50 \%$ MAA was used in the polymerization process. At any event, however, the apparent viscosity decreases by increasing the rate of shear within the range studied.

The shear thinning of these polymer solutions, containing long entangled and looping molecular chains could be explained by considering the polymer solution when the shear is not applied and after shear applied. Before applying the shear, the polymers will maintain

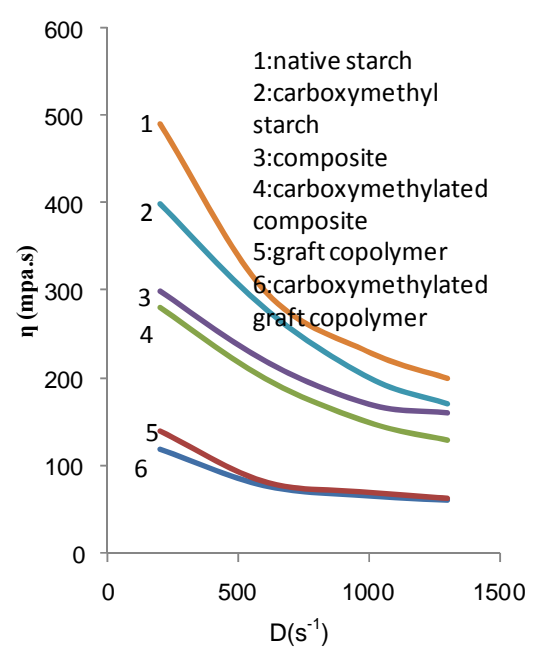

Figure 11. Effect of rate of shear on apparent viscosity when $75 \%$ MAA was used in the polymerization reaction. 


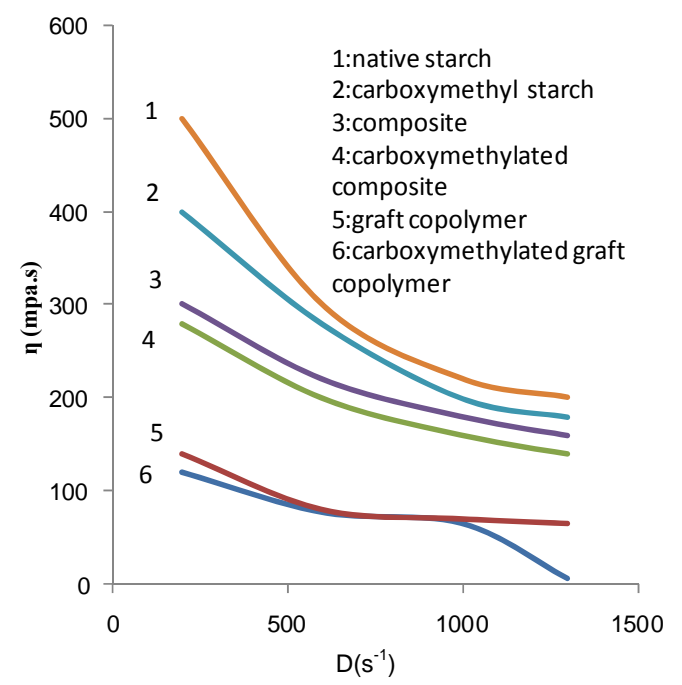

Figure 12. Effect of rate of shear on apparent viscosity when $100 \%$ MAA was used in the polymerization reaction.

internal order and, correspondingly, a sizeable internal resistance against flow, i.e., higher viscosity. On the other hand, with increasing shear rates, rod like particles suspended in the liquid will be turned lengthwise into the direction of the flow. Chain type molecules in a solution can disentangle, stretch and orient parallel to the driving force. Particles or molecular alignment allow particles and molecules to slip past each other more easily. This shows up as reduced viscosity.

The above shear thinning phenomenon in the field of rheology is called pseudoplasticity. This phenomenon is due to the gradual progressing structural breakdown upon deformation of the non-Newtonain system.

From Figures 11 and $\mathbf{1 2}$ the magnitude of change in the value of apparent viscosity with rate of shear was calculated and plotted in Figures 13-15. These values $\Delta \mathrm{St} / \Delta \mathrm{D}$ as set out in Table 2 reflect pseudoplasticity in each substrate. Accordingly pseudoplasticity follows the order: carboxymethyl copolymer $>$ carboxy-methyl starch $>$ carboxymethyl composite $>$ copolymer $>$ composite $>$ native starch.

The decreases of pseudoplasticity by chemical modification of starch through graft copolymerization with MAA and etherification through carboxymethylation indicates that starch undergoes molecular changes under the influence of both reactions as detailed above. It is certain, however, that the magnitude of changes brought about by the etherification reaction is greater than the graft copolymerization reaction as evidenced by the lower value of the pseudoplasticity found with the former.

Figure 16 shows the apparent viscosity (at constant rate of shear, temperature and solution concentration) of poly (MAA)-starch composite, poly (MAA)-starch graft copolymer and their carboxymethyl products versus

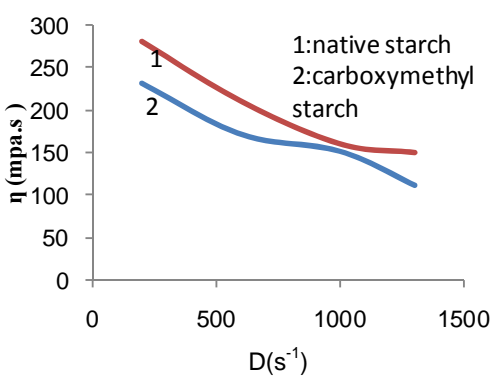

Figure 13. Effect of rate of shear on apparent viscosity of native starch and carboxymethylated starch.

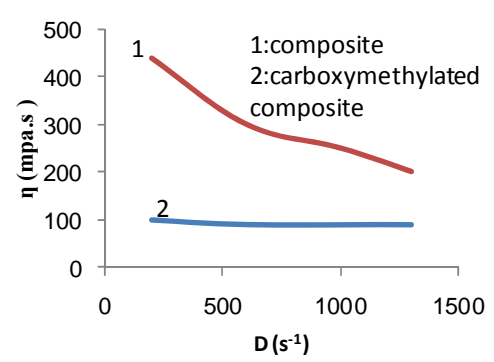

Figure 14. Effect of rate of shear on apparent viscosity of composite and carboxymethylated composite.

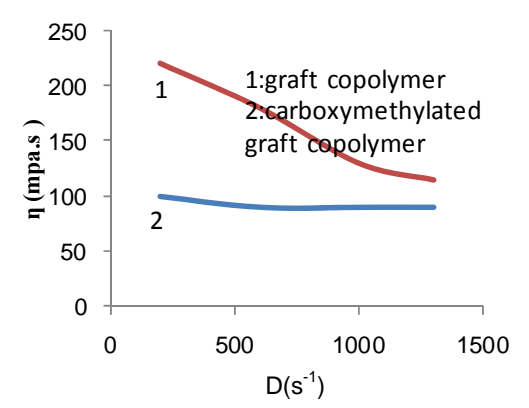

Figure 15. Effect of rate of shear on apparent viscosity of graft copolymer and its carboxymethylated derivatives.

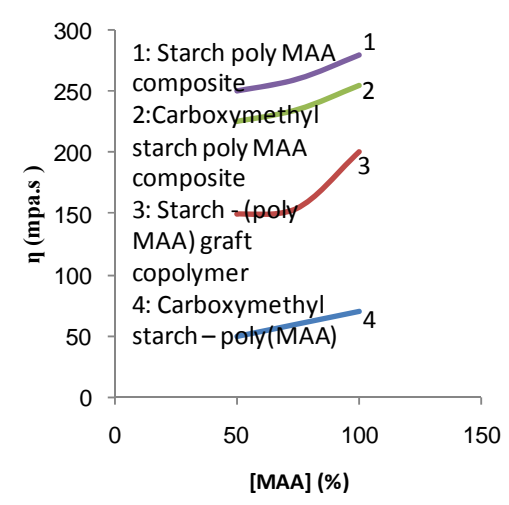

Figure 16. Effect of monomer concentration on the apparent viscosity at rate of shear $=516 \mathrm{~S}^{-1}$, concentration $=\mathbf{1 0} \%$, Temperature $=80^{\circ} \mathrm{C}$.

MAA concentration used in the polymerization. It is seen that regardless of monomer concentration, the viscosities of the different substrates follow the order: poly (MAA)- 
Table 2. Values of the slope $\eta / D$.

\begin{tabular}{lcccc}
\hline & \multicolumn{4}{c}{ Slope $=\eta / \mathrm{D}$} \\
\cline { 2 - 5 } Substrate & $0 \%$ & $50 \%$ & $75 \%$ & $100 \%$ \\
\cline { 2 - 5 } & & 0.13 & 0.21 & 0.26 \\
composite & & 0.17 & 0.16 & 0.16 \\
copolymer & & 0.16 & 0.16 & 0.22 \\
carboxymeth-yl Composite & & 0.03 & 0.07 & 0.09 \\
carboxymeth-yl copolymer & & & \\
native starch & 0.04 & & & \\
carboxymethyl starch & 0.04 & &
\end{tabular}

starch composite > poly (MAA)-starch graft copolymer $>$ carboxymethyl poly (MAA)-starch graft copolymer.

The above order signifies that the presence of poly (MAA) chains with starch in the form of graft (chemically bonded) and/or in the form of hompolymer (physically entangled) lowers the mobility of the macromolecules. Thus the physical entanglement of the poly (MAA) chains with themselves as well as with starch hydroxyls together with long growing chains and increased branching due to increase in monomer concentration would explain the higher viscosities exhibited by the composite and the graft copolymer. On the other hand, introduction of carboxymethyl groups in the starch backbone ruptures the physical forces (hydrogen bonds, Van der Waal's forces) between the starch hydroxyls and starch-poly (MAA) chains. As a result, the viscosity is reduced.

It is as well to emphasize that the apparent viscosity of poly (MAA)-starch composite sample and that of the graft copolymer sample were directly measured after their preparation. Similarly, samples were prepared, precipitated from the polymerization medium but then subjected to filtration, drying and re-drying in electric oven at $50^{\circ} \mathrm{C}$ till constant dry weight was obtained. The apparent viscosities of these dried samples were measured and compared with those directly measured after preparation.

Figures 17 and 18 show the apparent viscosities before and after precipitation and drying of carboxymethyl poly (MAA)-starch graft copolymer and composite, respectively, versus the monomer concentration used in the polymerization reaction. Obviously, the value of apparent viscosity increases significantly after precipitation and drying steps. This finding can be interpreted in terms of dehydration of the pendant carboxylic groups introduced in the molecular structure of starch through carboxymethylation and MAA polymerization. The entropy of these pendant carboxyl groups is reduced through dehydration step via carboxyl - carboxyl inter and intra anhydride formations. Such type of linking is accompanied by association and entanglement of the polymer, thereby increasing the apparent viscosity.

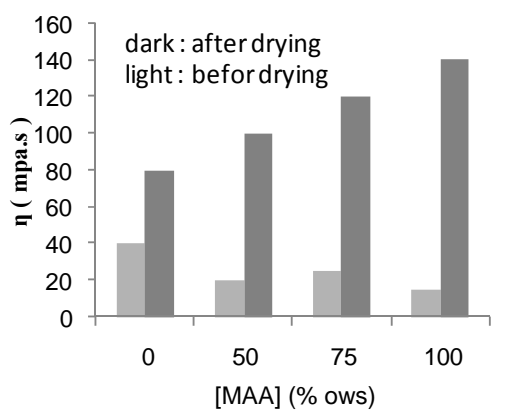

Figure 17. Comparison between the apparent viscosity of carboxmethylated starch-poly(MAA) graft copolymer before and after drying.

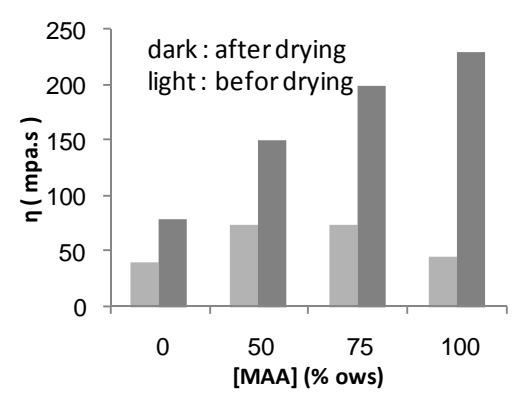

Figure 18. Comparison between the apparent viscosity of carboxmethylated starch-poly(MAA) graft copolymer before and after drying.

\section{Conclusions}

A new route was established for development of novel starch hybrids. This route comprises copolymerization of starch with MAA under a variety of conditions to yield to essential products, namely, poly (MAA)-starch graft copolymer and poly (MAA)-starch composite. While the composite represents the total polymerization products, the copolymer is freed from homopolymer. The composite and the copolymer along with native starch for comparison were then subjected to carboxymethylation under different conditions. Before and after carboxymethylation, these newly synthesized starch hybrids were monitored for carboxyl content and rheological properties. Main conclusions arrived at from the results obtained are given below.

1) The composite is less susceptible to carboxymethylation than the copolymer as the homopolymer acts as a diffusion barrier for etherifying agents to reach and react with starch hydroxyls.

2) In accordance with the above, the magnitude of poly (MAA) in the form of graft or homopolymer adversely affects the carboxymethylation reaction.

3) The native starch is more amenable to carboxymethylation than the composite and the copolymer and brings into focus the order: native starch > copolymer > composite.

4) The most appropriate conditions for carboxymethy- 
lation of the copolymer and the composite are: $[\mathrm{NaOH}]$ $=20 \%$ ows, $\left[\mathrm{ClCH}_{2} \mathrm{COOH}\right]=95 \%$ ows, reaction time $=$ $120 \mathrm{~min}$ and temperature $=70^{\circ} \mathrm{C}$.

5) Before carboxymethylation, the composite, copolymer and the native starch exhibit non-Newtonian thixotropic behavior which follows the order: composite > copolymer $>$ native starch whereas after carboxymethylation these products are characterized by non-Newtonian Pseudoplastic behavior.

6) The apparent viscosity decreases as the rate of shear increases irrespective of the nature of the starch product used but for a given rate of shear, and the apparent viscosity follows the order: native starch $>$ composite $>$ copolymer $>$ carboxymethyl composite $>$ carboxymethyl starch $>$ carboxymethyl copolymer.

7) Pseudoplasticity reveals an order which reverses to the above order.

8) The apparent viscosity increases by increasing poly (MAA) in the copolymer and composite.

9) Redrying of the copolymer and the composite after normal precipitation and drying causes a considerable enhancement in the apparent viscosity of these products.

\section{Acknowledgements}

The authors are indebted to late Profs. Dr.s A. Bayazeed and F. El. Sisi of the National Research Centre, Textile Reaserch Division, for their sound contribution in this research.

\section{REFERENCES}

[1] R. L. Whistler, "History and Future Expectations of Starch Uses," In: R. L. Whistler, J. N. BeMiller and E. F. Paschall, Eds., Starch Chemistry and Technology, 2nd Edition, Academic Press, London, 1984.

[2] J. R. Daniel, "Starch and Other Polysaccharides," Ullmann's Encyclopaedia of Industrial Chemistry, Vol. 25, 1994, pp. 1-63.
[3] O. B. Wurzburg, "Converted Starches," In: O. B. Wurzburg, Ed., Modified Starches: Properties and Uses, CRC Press, Florida, 1987.

[4] I. Abdel-Thalouth, L. H. Hana and A. A. Hebeish, "Oxidation of Carboxymethyl Starch with Sodium Hypochlorite," Textile Research Journal, Vol. 37, 1977, pp. 209211.

[5] A. Hebeish, M. H. El-Rafie, A. Higazy and M. Ramadan, "Synthesis, Characterization and Properties of Polyacrylamide-Starch Composites," Starch-Stärke, Vol. 48, No. 5, 1996 , pp. 175-179.

[6] A. Hebeish, M. H. El-Rafie, A. Higazy and M. A. Ramadan, "Preparation and Characterization of Water Soluble Poly(AA-)-Starch Composite," Al-Azhar Bulltien of Science, Vol. 6, No. 1 ,1995, pp. 789-793.

[7] A. Hebeish, A. Waly, M. H. El-Rafie and M. A. ElSheikh, "Synthesis and Characterization of New Polymeric Materials Based on Water Soluble Starch Composites," The 213th National Meeting, San Francisco, 1997.

[8] A. Hebeish, I. Khalil and A. Hashem, "Carboxymethylation of Starch and Oxidized Starche," Starch/Starke, Vol. 42, No. 5, 1990, pp. 185-191. http://dx.doi.org/10.1002/star.19900420506

[9] O. B. Wurzbrg, "Cross Linked Starches in Modified Starches Properties and Uses," In: O. B. Wurzburg, Ed., CRC Press, Florida, 1987.

[10] A. Hebeish, M. K. Beliakova and A. Bayazeed, "Improved Synthesis of Poly(Maa)-Starch Graft Copolymers," Journal of Applied Polymer Science, Vol. 68, No. 10, 1998, pp. 1709-1715. http://dx.doi.org/10.1002/(SICI)1097-4628(19980606)68: 10<1709::AID-APP21>3.0.CO;2-Q

[11] A. Hebeish and I. Khalil, "Characterization of the Reaction Products for Starch and Acrylonitrile," Starch/Starke, Vol. 40, No. 3, 1988, pp. 104-107.

[12] A. Hebeish, M. H. El-Rafie, A. Higazy and M. A. Ramadan, "Poly(Acrylic Acid)-Starch Composites. A Key for Improving Sizeability and Desizeability of Starch from Cotton Textiles," Starch/Starke, Vol. 44, 1992, pp. 101107. http://dx.doi.org/10.1002/star.19920440305 